\title{
The Implication of Low Back Pain and Its Severity in Young Male Soldiers of Republic of Korea
}

\author{
Min Ho Lee ${ }^{1,2}$, Taeyeob Lee ${ }^{1,3}$, Hoikeun Jeong ${ }^{1,4}$, Jaewoo Chung ${ }^{1,5 \bowtie}$ \\ 'Department of Neurosurgery, The Armed Forces II-Dong Hospital, Pocheon, Korea \\ ${ }^{2}$ Department of Neurosurgery, Samsung Medical Center, Sungkyunkwan University School of Medicine, Seoul, Korea \\ ${ }^{3}$ College of Nursing, Far East University, Eumseong, Korea \\ ${ }^{4}$ College of Nursing, Jesus University, Jeonju, Korea \\ ${ }^{5}$ Department of Neurosurgery, Hanyang University Medical Center, Seoul, Korea
}

Objective: Low back pain is common in South Korean soldiers, due to their arduous military training and physical activity. The aim of this study is to determine factors affecting the degree of low back pain in young male soldiers including objective radiological findings. Methods: From November 2014 to March 2015, 262 patients with recently developed symptoms were enrolled. The patients completed a questionnaire. Questionnaire and information from MRI, X-ray and computed tomography images were reviewed. The VAS-LBP, VASRP, and ODI were evaluated to assessment the degree of symptoms. All patients were males in their $10 \mathrm{~s}$ and $20 \mathrm{~s}$ (range 18-28 years). Results: All patients were males in their $20 \mathrm{~s}$ (median age 21 years, range 18-28 years). Military rank included private soldiers ( $\mathrm{n}=29$, $12.3 \%)$, private first-class $(n=93,39.4 \%)$, corporals $(n=63,26.7 \%)$, sergeants $(n=38,16.1 \%)$, and executive members over officers ( $n=13$, $5.5 \%)$. Symptoms, other risk factors, and radiologic findings were compared. We could not reach statistically significant result for any risk factors for degenerative lumbar disc disorder. Military rank was negatively related with the degree of pain, although there was no difference of severity of degenerative lumbar disc disorder between each rank. Conclusion: Military rank was a considerable social factor associate with the degree of low back pain in young male soldiers. Careful evaluation and treatment with systematic management of soldiers with low back pain seems prudent.

Key Words: Lumber disc degeneration; Lumber disc herniation; Young; Military.

$\triangle$ Corresponding author: Jaewoo Chung, Department of Neurosurgery, Hanyang University Medical Center, 222-1 Wangsimni-ro, Seongdong-gu, Seoul 04763, Korea. Tel: 82-2-2290-8496, Fax: 82-2-2281-0954, E-mail: jaewoo.chung.md@gmail.com

\section{INTRODUCTION}

South Korea (Republic of Korea) maintains a military presence because it is at armistice state with North Korea (Democratic People's Republic of Korea). There is a mandatory military enlistment system exists in South Korea. According to the Ministry of National Defense, about $90 \%$ of Korean men have performed 2 years of mandatory military service. During the 2 years of military service, medical care is provided as a public health service offering for free.

Low back pain is very common symptom in South Korean soldiers and the likely result of arduous military training and physical activity. Low back pain has a great portion in military medicine, and its portion is growing ${ }^{15,18,19)}$. Much time and money are spent diagnosing and treating soldiers with low back pain, which can remove soldiers from action. Most soldiers had not experienced low back pain prior to their military service. These patients do not usually have significant degenerative changes in the spine, as biomechanical stress is a typical cause of low back pain. Low back pain involves a complex combination of symptoms associated with physiological, psychological, and behavioral factors ${ }^{1,13,14,24)}$. Low back pain can be aggravated by psychological factors and reluctance to seek treatment; thus, symptoms in military personnel may not be adequately addressed. Radiological findings do not always correlate with clinical findings, making it occasionally very difficult to clarify symptoms because of the various psychological factors including secondary gains associated with military life ${ }^{1,4,16,17,28)}$.

The aim of this study was to determine factors affecting the degree of low back pain in young male soldiers including objective radiological findings. In addition, we investigated social and environmental factors in military life. 


\section{MATERIALS AND METHODS}

Patients were visited our outpatient department of military hospital. A total of 262 patients with low back pain as a newly emerging symptom and chief complaint indicative of intervertebral disc herniation who had received lumbar magnetic resonance imaging (MRI) for the first time from November 2014 to March 2015, 262 patients were enrolled. All patients had complained of low back pain for more than 3 months. Patients with acute pain due to trauma, such as slip down, fall down, traffic accident etc. - were not included. Twenty-one patients were excluded due to a lack of a computed tomography (CT) or simple $\mathrm{X}$-ray image, and five patients were excluded for an incomplete questionnaire. Finally, 236 patients were enrolled in this study.

The questionnaire included information about enlisted date, military rank, assigned position and specialty, military physical examination grade, and current symptoms. The visual analogue scale (VAS) for low back pain (VAS-LBP), VAS for radiating pain (VAS-RP), and the Oswestry Disability Index (ODI) were evaluated to assess symptoms. All data were culled prospectively from an acquired patient database. Written informed consent was obtained from all subjects. The subjects were carefully screened using a modified low back pain questionnaire and history taking. Previous studies ${ }^{2,20,21)}$ revealed that lumbar disc degeneration is significantly associated with overweight. However, body mass index was not a consideration in the present study, as overweight and obese individuals are prevented from military service, in advance.

The study protocol was reviewed and approved by the institutional review board of the Korean Military Medical Research Project (AFMC-15001-IRB-15-001) and was adhered to the recommendations for biomedical research involving human subjects under the Declaration of Helsinki (1975).

\section{Radiographic and MRI evaluation}

MRIs were acquired in each patient using standard 1.5T scanners and were included T2-weighted sagittal and axial images.

\section{Disc herniation}

Disc herniation was assessed on a T2-weighted axial image of the index disc levels. It was classified as 1) normal (when the disc did not reach beyond the borders of the adjacent vertebral bodies), 2) bulging (circumferential, symmetric disc extension around the vertebral border), 3) protrusion (focal or asymmetric disc extension beyond the vertebral border with the base against the parent disc broader than any other diameter of the protrusion), 4) extrusion (focal and obvious disc extension beyond the vertebral border, with the base against the parent disc narrower than the diameter of the extruded material itself) with previously defined terminology $y^{23)}$.

\section{Disc degeneration}

Disc degeneration was assessed quantitatively based on nu- cleus pulposus signal intensity. Nucleus pulposus signal intensity was measured on T2-weighted mid-sagittal images, according to the modified Pfirrmann grading system. ${ }^{11)}$

\section{Other pathology}

The morphological type of lumbosacral transitional vertebra (LSTV) was identified based on a previously described classification $^{6}$. Castellvi described a radiographic classification system identifying four types of LSTV based on morphological characteristics. Type I includes unilateral (Ia) or bilateral (Ib) dysplastic transverse processes, measuring at least $19 \mathrm{~mm}$ in width. Type II exhibits incomplete unilateral (IIa) or bilateral (IIb) lumbarization/sacalization with an enlarged transverse process that has a pseudo-arthrosis between itself and the sacrum. Type III describes unilateral (IIIA) or bilateral (IIIb) lumbarization/sacralization with complete osseous fusion of the transverse process to the sacrum. Type IV involves a unilateral pseudo-arthrosis with osseous fusion on the contralateral side ${ }^{6}$. Type I has been considered a variation of normal due to the presence of a mobile disc caudal to the vertebra and was not defined as a transitional vertebra in this study. Spondylolysis was diagnosed by oblique view of lumbar $\mathrm{x}$-ray or CT scan.

\section{Statistical analysis}

Spearman's rho test was used to detect correlations between variables. The Mann-Whitney U-test was used to compare the effect of categorized risk factors. Statistical analyses were carried out using commercial software (SPSS, version 20; IBM, Armonk, NY, USA). A $p$-value $<0.05$ was considered significant.

\section{RESULTS}

All 236 patients were males in their 10s and 20s (median age, 21 years; range, 18-28 years). The military ranks were comprised of private soldiers $(\mathrm{n}=29,12.3 \%)$, private first class $(n=93,39.4 \%)$, corporals $(n=63,26.7 \%)$, sergeants $(n=38$, $16.1 \%)$, and executive members over the rank of officer $(n=13$, 5.5\%). All patients had specialties. Several work-related risk factors were considered based on specialty. Thirty-three (14.0\%) patients were office workers, 43 (18.2\%) were drivers and 155 (65.7\%) had a specialty of heavy lifting. In the questionnaire responses, the median VAS-LBP score was 6 (range, $0-9$ ) and the median VAS-RP score was 4 (range, $0-9$ ). Fifty nine patients did not complain of radicular pain. The median ODI score was $32 \%$ (range, $2-90 \%$ ). The CT scans and/or X-rays showed that 26 (11.0\%) patients had spondylolysis and 16 (6.8\%) had LSTV $>$ grade 2 . According to the modified Pfirrmann grading system, 27 patients (11\%) were grade 1, 54 patients (23\%) were grade 2, 53 patients (22\%) were grade 3,48 patients (20\%) were grade 4, 44 patients (19\%) were grade 5 , and 10 patients (4\%) were grade 6 . There were no patients over grade 7 (Table 1 ). 


\section{Correlation between patient factors, pain, and MRI status}

The VAS-LBP, VAS-RP, and ODI scores from the questionnaire and MRI status (modified Pfirrmann grade, disc herniation) were compared but no significant difference were detected. No difference was found between military rank and MRI status (modified Pfirrmann grade, disc herniation). Patients with lower military rank displayed significantly higher VAS-LBP, VAS$\mathrm{RP}$, and ODI score $(p<0.001,<0.001$, and $=0.004$, respectively) (Fig. 1). No associations were found between sitting, heavy lifting, and driving work-related functions and MRI status (modified Pfirmann grade, disc herniation). However, patients with

Table 1. Characteristics of patients and radiologic findings

\begin{tabular}{|c|c|}
\hline & $\begin{array}{l}\text { Patients number } \\
\quad(\mathrm{n}=236)\end{array}$ \\
\hline Age (median, range; yr) & $21(18-28)$ \\
\hline Sex (male; n, \%) & $236,100 \%$ \\
\hline \multicolumn{2}{|l|}{ Military rank (n, \%) } \\
\hline Private soldiers & $29(12.3 \%)$ \\
\hline Private first classes & $93(39.4 \%)$ \\
\hline Corporals & $63(26.7 \%)$ \\
\hline Sergeants & $38(16.1 \%)$ \\
\hline Executive members (over officers) & $13(5.5 \%)$ \\
\hline \multicolumn{2}{|c|}{ Military specialty (working risk factors) $(\mathrm{n}, \%)$} \\
\hline Sitting (office working) & $33(14.0 \%)$ \\
\hline Heavy lifting & $155(65.7 \%)$ \\
\hline Driving & $43(18.2 \%)$ \\
\hline \multicolumn{2}{|l|}{ Symptom } \\
\hline \multicolumn{2}{|l|}{ VAS-LBP } \\
\hline Median, range & $6(0-9)$ \\
\hline \multicolumn{2}{|l|}{ VAS-RP } \\
\hline Median, range & $4(0-9)$ \\
\hline Yes/no & $177 / 59$ \\
\hline \multicolumn{2}{|l|}{ ODI (\%) } \\
\hline Median, range & $32(2-90)$ \\
\hline$<50 / \geq 50$ & $200 / 36$ \\
\hline \multicolumn{2}{|l|}{ Radiologic findings } \\
\hline \multicolumn{2}{|l|}{ CT or X-ray $(\mathrm{n}, \%)$} \\
\hline Spondyloysis & $26(11.0 \%)$ \\
\hline Lumbo-sacral transitional vertebra & $16(6.8 \%)$ \\
\hline \multicolumn{2}{|l|}{ MRI } \\
\hline \multicolumn{2}{|l|}{ Pfirrmann grading system (n, \%) } \\
\hline Grade 1 & $27(11 \%)$ \\
\hline Grade 2 & $54(23 \%)$ \\
\hline Grade 3 & $53(22 \%)$ \\
\hline Grade 4 & $48(20 \%)$ \\
\hline Grade 5 & $44(19 \%)$ \\
\hline Grade 6 & $10(4 \%)$ \\
\hline \multicolumn{2}{|l|}{ Disc herniation $(\mathrm{n}, \%)$} \\
\hline Normal & $69(29.2 \%)$ \\
\hline Diffuse bulging & $75(31.8 \%)$ \\
\hline Protrusion & $64(27.1 \%)$ \\
\hline Extrusion & $28(11.9 \%)$ \\
\hline
\end{tabular}

a risk factor of sitting had higher VAS-LBP, VAS-RP, and ODI scores ( $p<0.001, p=0.045$, and $p<0.001$, respectively). Patients with a risk factor of heavy lifting had more higher VAS-LBP and ODI scores ( $p<0.001$ and $p=0.011$, respectively) Suspicious
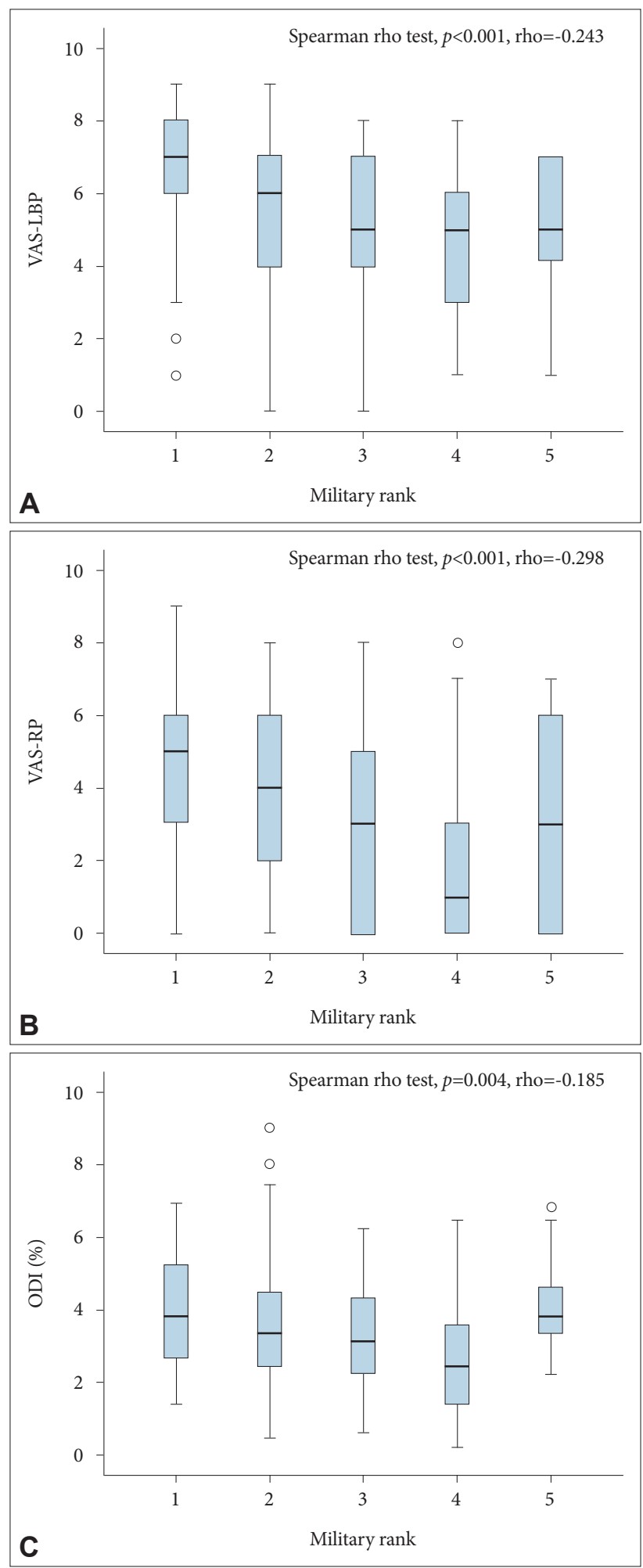

Fig. 1. Visual analog scale-low back pain scores (A), Visual analog scale-radiating pain scores (B), and Oswestry Disability Index (C) according to military rank showed a negative relationship. $1:$ private soldiers; 2 : private first-class; 3 : corporals; 4 : sergeants; 5 executive members over officers. 
Table 2. Correlation between risk factors (specialty, and radiologic findings) and symptom or MRI findings

\begin{tabular}{|c|c|c|c|c|c|c|}
\hline \multicolumn{2}{|l|}{ Risk factors } & $\begin{array}{l}\text { VAS-LBP } \\
p \text {-value }\end{array}$ & $\begin{array}{l}\text { VAS-RP } \\
p \text {-value }\end{array}$ & $\begin{array}{c}\text { ODI } \\
p \text {-value }\end{array}$ & $\begin{array}{l}\text { Modified Pfirrmann grade } \\
\quad p \text {-value }\end{array}$ & $\begin{array}{c}\text { Disc herniation (grade) } \\
p \text {-value }\end{array}$ \\
\hline \multicolumn{7}{|l|}{ Specialty } \\
\hline Sitting (office working) & $33(14.0 \%)$ & $<0.001^{*}$ & $0.022^{*}$ & $<0.001^{*}$ & 0.127 & 0.171 \\
\hline Heavy lifting & $155(65.7 \%)$ & $<0.001^{*}$ & 0.148 & $0.005^{*}$ & 0.610 & 0.141 \\
\hline Driving & $43(18.2 \%)$ & 0.386 & 0.449 & 0.350 & 0.616 & 0.444 \\
\hline \multicolumn{7}{|l|}{ Radiologic findings } \\
\hline Spondylolysis & $26(11.0 \%)$ & 0.442 & 0.221 & 0.454 & 0.806 & 0.066 \\
\hline LSTV & $16(6.8 \%)$ & 0.392 & 0.198 & 0.164 & 0.071 & 0.420 \\
\hline
\end{tabular}

LSTV : lumbosacral transitional vertebrae

risk factors from radiologic pathology (LSTV and spondylolysis) were compared with MRI status (modified Pfirrmann grade, disc herniation) and symptoms. However, no differences were observed between variables (Table 2).

\section{DISCUSSION}

\section{Symptom and military rank}

Lower ranking soldiers complain more of pain, perhaps reflecting their ongoing adaptation to their new circumstances ${ }^{15)}$. The present study showed similar results. Lower ranked soldiers tended to have higher VAS scores; these individuals had a tendency to overstate their difficulties. We expected that the ODI would be more objective than the VAS. However, the ODI as a self-questionnaire had no value as an objective pain scale. Pain tolerance of lower ranked soldiers who must adapt to military service can be influenced by various factors. There is no doubt that motivation to serve is highly variable from individual to individual at their initial entry into the military. It is reasonable to assume that lower ranking soldiers have a decrease in perceived control of their environment. These soldiers subsequently report worse symptoms with similar radiographic pathology. However, no significant difference was observed between rank and MRI findings. This result contrasts with a previous study, which found a correlation between military rank and MRI findings ${ }^{15)}$. Although this is a cross-sectional study, evidence of worsening of disc degeneration during military service is quite low.

\section{Symptoms and radiologic findings}

Radiological findings are sometimes regarded as more reliable and significant than clinical symptoms because they have a level of objectivity. However, symptoms do not always match radiological severity. Lumbosacral transitional vertebra is one of the most common congenital anomalies of the lumbosacral spine with a prevalence of $7-30 \%{ }^{7,8,27}$. An association between the lumbosacral transitional vertebra and disc degeneration has been reported ${ }^{3,22,25)}$. We did not find such an association. Spondylolysis occurs in $6 \%$ of the general population and approximately $75 \%$ of these cases will develop spondylolisthesis ${ }^{5,26)}$. The present study showed no evidence of an association between spondylolysis and symptoms.

\section{Care of low back pain during military service}

An unfamiliar environment, isolation from family or society, and anxiety associated with adaptation to an obey-command society may be related to low back pain. We should not consider malingering to lower ranked soldiers who complain of low back pain. Military rank is an environmental or psychological factor associated with low back pain, and the physician should consider the situation of the patient.

It is not possible to perform a lumbar MRI on every patient due to cost; thus, careful selection of patients by history taking and physical examination is necessary. Several studies have reported the importance of early physiotherapy for patients with low back pain and provided encouraging results" ${ }^{19)}$ A "low back pain school" was first introduced nearly 40 years ago and has become popular". The primary purpose of "low back pain school" is to educate patients about the physiology and movement of the spine and their influence on everyday life. The aim is to promote patient-oriented pain care ${ }^{12)}$. Most (80-90\%) patients with low back pain recover somewhat within 3 months with proper early physiotherapy ${ }^{10)}$. Early physiotherapy can be an efficient treatment modality for patients with low back pain who have no lumbar lesions on MRI or for whom MRI has not been conducted and may have merit in military care. It is difficult to propose an ultimate solution for low back pain during military service. However systematic management with physiotherapy between the military hospital and medical corps could be an answer. This systematic management can provide continuous care for patients.

This study is limited by the small sample size and exclusive involvement of military personnel. A larger study is warranted before making definitive recommendations.

\section{CONCLUSION}

The aim of the study was to find out the cause of low back pain, especially focused in military unit. It revealed that lower ranked soldiers tend to overstate their pain intensity. It is difficult to provide adequate medical care objectively to those patients. Low back pain can be caused by multiple factors. And the physician should not ignore psychological and environmental factors. 
It would be useful to encourage systematic management of physiotherapy through a low back pain school for patients with low back pain when reinforcing the relationship between medical corps dispensary and the military hospital.

\section{- Acknowledgements}

This work was supported by the Korean Military Medical Research Project funded by the ROK Ministry of National Defense (ROK-MND2015-KMMRP-001).

\section{REFERENCES}

1. Beattie PF, Meyers SP, Stratford P, Millard RW, Hollenberg GM : Associations between patient report of symptoms and anatomic impairment visible on lumbar magnetic resonance imaging. Spine (Phila Pa 1976) 25 : 819828,2000

2. Beutler WJ, Fredrickson BE, Murtland A, Sweeney CA, Grant WD, Baker $\mathrm{D}$ : The natural history of spondylolysis and spondylolisthesis : 45-year follow-up evaluation. Spine (Phila Pa 1976) 28 : 1027-1035; discussion 1035, 2003

3. Bonaiuti D, Faccenda I, Flores A : [Sacralization of the 5th lumbar vertebra and backache : what's the possible relationship?]. Med Lav 88 : 226-236, 1997

4. Borenstein DG, O’Mara JW Jr, Boden SD, Lauerman WC, Jacobson A, Platenberg $C$, et al. : The value of magnetic resonance imaging of the lumbar spine to predict low-back pain in asymptomatic subjects : a seven-year follow-up study. J Bone Joint Surg Am 83-A : 1306-1311, 2001

5. Cassidy RC, Shaffer WO, Johnson DL : Spondylolysis and spondylolisthesis in the athlete. Orthopedics $28: 1331-1333,2005$

6. Castellvi AE, Goldstein LA, Chan DP : Lumbosacral transitional vertebrae and their relationship with lumbar extradural defects. Spine (Phila Pa 1976) 9 : 493-495, 1984

7. Delport EG, Cucuzzella TR, Kim N, Marley J, Pruitt C, Delport AG : Lumbosacral transitional vertebrae : incidence in a consecutive patient series. Pain Physician 9: 53-56, 2006

8. Dzupa V, Slepanek M, Striz M, Krbec M, Chmelova J, Kachlik D, et al. : Developmental malformations in the area of the lumbosacral transitional vertebrae and sacrum : differences in gender and left/right distribution. Surg Radiol Anat 36 : 689-693, 2014

9. Forssell MZ: The back school. Spine (Phila Pa 1976) 6 : 104-106, 1981

10. Garvey TA, Marks MR, Wiesel SW : A prospective, randomized, doubleblind evaluation of trigger-point injection therapy for low-back pain. Spine (Phila Pa 1976) 14: 962-964, 1989

11. Griffith JF, Wang YX, Antonio GE, Choi KC, Yu A, Ahuja AT, et al. : Modified Pfirrmann grading system for lumbar intervertebral disc degeneration. Spine (Phila Pa 1976) 32 : E708-E712, 2007

12. Hall H : The Canadian Back Education Units. Physiotherapy 66 : 115117,1980

13. Hollingworth W, Dixon AK, Todd CJ, Bell MI, Antoun NM, Arafat Q, et al. : Self reported health status and magnetic resonance imaging findings in patients with low back pain. Eur Spine J $7: 369-375,1998$

14. Jarvik JJ, Hollingworth W, Heagerty P, Haynor DR, Deyo RA : The Longitudinal Assessment of Imaging and Disability of the Back (LAIDBack) Study : baseline data. Spine (Phila Pa 1976) 26 : 1158-1166, 2001

15. Kang SH, Yang JS, Cho YJ, Park SW, Ko KP : Military rank and the symptoms of lumbar disc herniation in young Korean soldiers. World Neurosurg 82 : e9-e14, 2014

16. Kim JB, Lee YS, Lee SC : Psychiatric Study of Patients Complaining Low back pain with or without Sciatica. J Korean Mil Med Assoc 18 : 134-141, 1987

17. Kim TW, Oh CH, Shim YS, Yoon SH, Park HC, Park CO : Psychopathological influence of lumbar disc herniation in male adolescent. Yonsei Med J 54 : 813-818, 2013

18. Lee SH, Oh CH, Yoon SH, Park HC, Park CO : Prevalence and geographic distribution of herniated intervertebral disc in Korean 19-year-old male from 2008 to 2009 : a study based on Korean conscription -national and geographic prevalence of herniated intervertebral disc in Korean 19YO male. Yonsei Med J 54 : 1098-1103, 2013

19. Lee SJ, Kim KE, Lee KJ, Lee JH : Clinical effectiveness of low back pain school in Korean Army. J Korean Mil Med Assoc 44 : 21-44, 2013

20. Liuke M, Solovieva S, Lamminen A, Luoma K, Leino-Arjas P, Luukkonen $\mathrm{R}$, et al. : Disc degeneration of the lumbar spine in relation to overweight. Int J Obes (Lond) 29 : 903-908, 2005

21. Livshits G, Popham M, Malkin I, Sambrook PN, Macgregor AJ, Spector T, et al. : Lumbar disc degeneration and genetic factors are the main risk factors for low back pain in women : the UK Twin Spine Study. Ann Rheum Dis 70 : 1740-1745, 2011

22. Luoma K, Vehmas T, Raininko R, Luukkonen R, Riihimaki H : Lumbosacral transitional vertebra : relation to disc degeneration and low back pain. Spine (Phila Pa 1976) 29 : 200-205, 2004

23. Milette PC : The proper terminology for reporting lumbar intervertebral disk disorders. AJNR Am J Neuroradiol 18 : 1859-1866, 1997

24. Secer M, Nacar OA, Muradov MJ, Altintoprak F, Kabali B, Senol Z, et al. : Nonspecific low back pain in a group of young adult men. Turk Neurosurg $21: 135-139,2011$

25. Sekharappa V, Amritanand R, Krishnan V, David KS : Lumbosacral transition vertebra : prevalence and its significance. Asian Spine J 8 : 51-58, 2014

26. Toueg CW, Mac-Thiong JM, Grimard G, Poitras B, Parent S, Labelle H : Spondylolisthesis, Sacro-Pelvic Morphology, and Orientation in Young Gymnasts. J Spinal Disord Tech 28 : E358-E364, 2015

27. Vergauwen S, Parizel PM, van Breusegem L, Van Goethem JW, Nackaerts Y, Van den Hauwe L, et al. : Distribution and incidence of degenerative spine changes in patients with a lumbo-sacral transitional vertebra. Eur Spine J 6 : 168-172, 1997

28. Videman T, Battie MC, Gibbons LE, Maravilla K, Manninen H, Kaprio J : Associations between back pain history and lumbar MRI findings. Spine (Phila Pa 1976) 28 : 582-588, 2003 